\title{
Potential binding efficiency of antiviral drug lopinavir targeted to the catalytic dyad, His41 - Cys145 of SARS CoV -2 Main protease \\ S.Muthu Raj ${ }^{1}$, M.Manohar ${ }^{1}$, M.Mohan ${ }^{* 2}$, Ganesh $\mathrm{P}^{3}$, Marimuthu $\mathrm{K}^{4}$
}

\author{
* Corresponding author \\ 1.Department of Microbiology, Sadakathullah Appa College (Autonomous),Tamil Nadu,India \\ 2. Department of Chemistry, Mahendra Engineering College (Autonomous), Tamil Nadu, India \\ 3. Department of Microbiology, Annamalai University, Tamilnadu, India \\ 4. Department of Biotechnology, AIMST University, Bedong, Malaysia
}

\begin{abstract}
The spread of SARS CoV 2 across the globe rushed the scientific community to find out the potential inhibitor for controlling the viral disease. The main protease (Mpro) or Chymotrypsin protease (3CLpro) is involved in the cleavage of polyproteins, duplication of intracellular materials and release of nonstructural proteins. Cys-His catalytic dyad is located in the SARS-CoV Mpro which is the substrate-binding site located in domains I and II. There are many approved drugs that have their active protease inhibition capability. The targeting of the active site of the main protease is the better option to fight against the viral population. Lopinavir, ritonavir, Remdesivir and Chloroquine are some of the drug candidates considered to be involved in the treatment of SARS CoV 2 under emergency situation as a trial basis. In the present investigation we used lopinavir as a drug to bind the catalytic dyad His41, Cys145 of main protease. The minimum binding of energy of $-11.45 \mathrm{kcal} / \mathrm{mol}$ observed with the binding of Cys 145 and $-10.93 \mathrm{kcal} / \mathrm{mol}$ was noted with the residue His41. The inhibition constant was also found to be relevant to the binding efficiency of the drug. This is considered to be a model drug target which is initiating the finding of many new drugs to target the current outbreak created by the virus SARS.CoV - 2 .
\end{abstract}

Key words :SARS CoV-2, Main Protease, His41-Cys145, lopinavir, binding energy

\section{Introduction}

Severe Acute Respiratory Syndrome CoronaVirus 2 (SARS-CoV-2) is a RNA virus causing a highly infectious disease called Coronavirus disease (COVID-19). The name of the virus SARS CoV 2 announced by the International Committee on Taxonomy of Viruses (ICTV). The past two decades the severity of coronavirus faced by the human population in which SARS-CoV emerged during the year 2002 and in the year 2012 it is reported that the Middle East Respiratory Syndrome Coronavirus (MERS-CoV). The SARS CoV 2 is reported at the end of the year 2019 in Wuhan,China. The important function mediated by the main protease of $\mathrm{CoV}$ is to split up the poly protein 1a (pp1a) and polyprotein 1ab (pp 1ab) and it is considered to be a target to develop drug candidates. The catalytic dyad Cys145-His41 is an efficient functional target (Wu. et.al.2013). 
Research groups and pharmaceutical companies across the world are elaborately involved to develop vaccines and drug molecules as a prophylactic and treatment options for SARS CoV2. The conventional process of drug development is a time consuming process to get the right candidate for drug or vaccine. Alternatively the use of repurposed drugs is a better solution for the current pandemic situation. In view of the above situation, we proposed to study the binding efficiency of lopinavir with the SARS CoV2 Mpro by molecular studies.

\section{Materials and methods}

Protein : Main Protease (Mpro) or 3 Chymotrypsin like protease (3CLpro) is used for the present study and its structure obtained from Protein Data Bank (PDB) (Liu.et.al. 2020) The molecular weight of the protease is $34.51 \mathrm{kDa}$ with atom count of 2500 and 312 residues bearing two unique protein chains. Binding pocket of the Mpro showing His41-Cys145 Main protease monomer contains three domains. Domains I and II (residues 8-101 and 102-184) are made of antiparallel $\beta$-barrel structures Domain III (201-303).

\section{Preparation of Protein data bank parameter file:}

Molecular studies was performed with the help of autodocking tools and cygwin tools. For this current study 1 ligand and 1 receptor was used for finding the ligand protein interaction. The 3D structure was retrieved with the help of open babel software. Ligand and receptor file was obtained from protein data bank and pubchem sites. Finally the binding energy and RMSD values are obtained from autodock log file.

\section{Figure 1 : Binding pocket showing Cys-His dyad of SARS Cov Main protease}




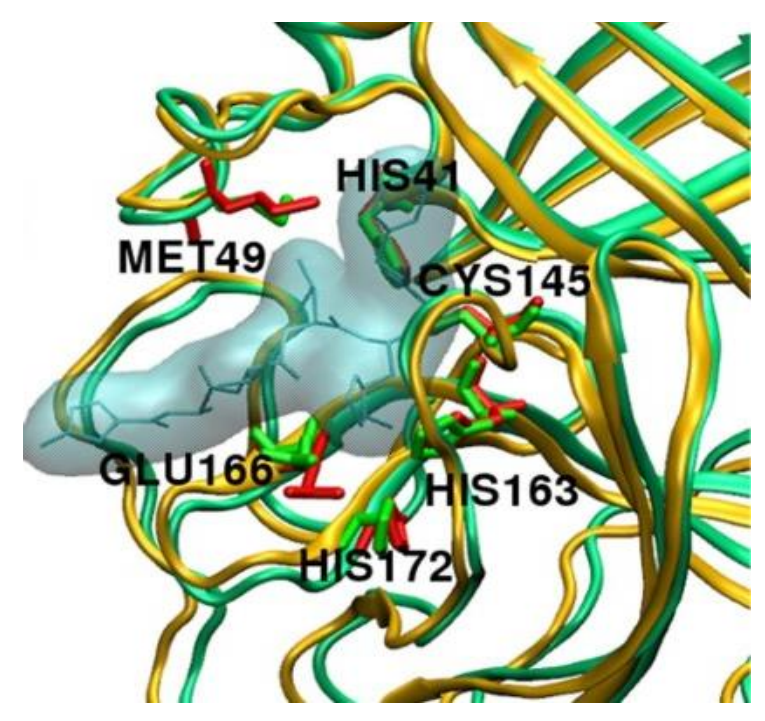

Drug: The drug candidate used for the present docking trial is Lopinavir with Pubchem ID:92727 and its molecular formula is C37H48N4O5.

\section{Results and Discussion}

The results observed during the molecular docking studies of main protease of SARS CoV 2 with lopinavir was presented in the table 1 . The present investigation revealed that the minimum binding energy of $-11.25 \mathrm{kcal} / \mathrm{mol}$ and mean value of $-10.32 \mathrm{kcal} / \mathrm{mol}$ were obtained with the Cys 145 residue. The average inhibition constant of $26.24 \mathrm{nM}$ observed with the residue Cys145 and $44.65 \mathrm{nM}$ with the His 41 . The minimum binding energy with His 41 was $-10.93 \mathrm{kcal} / \mathrm{mol}$ bearing average value of $-10.29 \mathrm{kcal} / \mathrm{mol}$. The other parameters like intermolecular energy, vanderwaals bonding energy, Hydrogen bonding and desolve energy and electrostatic energy also found to be better with the binding pockets. Symmetrical Cys-His dyad situated in opposite manner which are acting independently (Shi. Etal.2008).

Table.1: Results observed during docking trials

\begin{tabular}{|c|c|c|c|c|c|}
\hline Amino acid & $\begin{array}{c}\text { Binding } \\
\text { energy } \\
(\mathrm{Kcal} / \mathrm{mol})\end{array}$ & $\mathrm{Ki}(\mathrm{nM})$ & $\begin{array}{c}\text { Inter } \\
\text { Mol.Energy } \\
(\mathrm{Kcal} / \mathrm{mol})\end{array}$ & $\begin{array}{c}\text { vdW+H } \\
\text { bond+desol } \\
\text { energy } \\
(\mathrm{Kcal} / \mathrm{mol})\end{array}$ & $\begin{array}{c}\text { Electrostatic } \\
\text { energy } \\
(\mathrm{Kcal} / \mathrm{mol})\end{array}$ \\
\hline \multirow{2}{*}{ Cys145 } & -11.25 & 5.64 & -15.03 & -13.62 & -1.42 \\
\cline { 2 - 6 } & -10.44 & 63.34 & -14.34 & -13.42 & -0.92 \\
\hline
\end{tabular}




\begin{tabular}{|c|c|c|c|c|c|}
\hline & -9.26 & 9.74 & -13.36 & -12.76 & -0.6 \\
\hline Average & -10.32 & 26.24 & -14.24 & -13.27 & -0.98 \\
\hline SD & 1.00 & 32.19 & 0.84 & 0.45 & 0.41 \\
\hline \multirow{3}{*}{ His41 } & -10.93 & 9.74 & -14.55 & -13.07 & -1.48 \\
\cline { 2 - 6 } & -10.03 & 44.65 & -13.45 & -13.29 & -0.16 \\
\cline { 2 - 6 } & -9.92 & 53.51 & -13.03 & -12.38 & -0.64 \\
\hline Average & -10.29 & 35.97 & -13.68 & -12.91 & -0.76 \\
\hline SD & 0.55 & 23.14 & 0.78 & 0.47 & 0.67 \\
\hline
\end{tabular}

Figure 2. Binding nature of lopinavir with the active sites of main protease

\begin{tabular}{|l|l|}
\hline Cys 145 with binding energy of $-10.44 \mathrm{kcal} / \mathrm{mol}$ & Cys 145 with binding energy of $-9.26 \mathrm{kcal} / \mathrm{mol}$ \\
\hline & \\
\hline His41 with binding energy of $-10.03 \mathrm{kcal} / \mathrm{mol}$ & His 41 with binding energy of $-9.92 \mathrm{kcal} / \mathrm{mol}$ \\
\hline
\end{tabular}




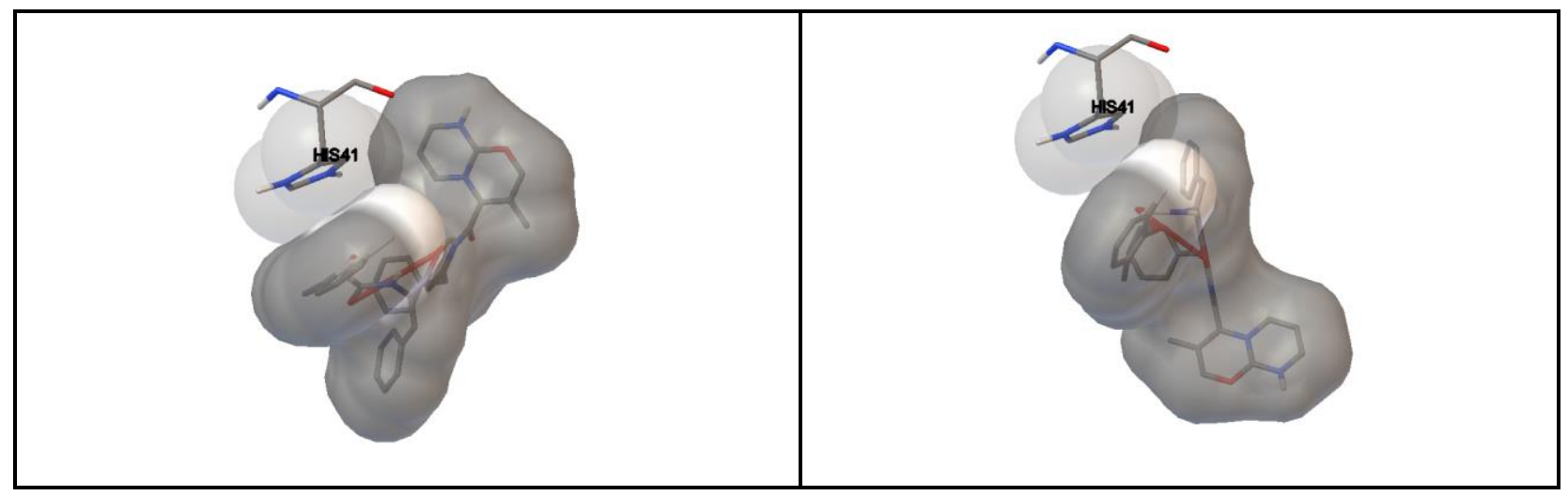

The better binding poses were given the figure 2 which is showing minimum binding with the Cys145 and His41 residues. The combination of lopinavir and ritonavir which are observed to be inhibitors of HIV-1 protease are efficient inhibitors for Mpro of SARS CoV (Nutho.et.al.2020). Binding efficiency of lopinavir observed by Md Fulbabu et.al (2020). The remdesivir, lopinavir, and ritonavir are effective antiviral drugs used to treat new coronaviruses (Mothay and Ramesh. 2020). Cheng et.al (2004) recommended that the lopinavir/ritonavir for clinical trials for the disease. The reduction of mortality rate was observed with combination of lopnavir and ritonavir (Chan. et.al 2003) and lopinavir inhibited the cytopathic effect (Chu. et.al. 2004).

\section{Conclusion}

Inhibition of Mpo activity is efficient to control the disease by preventing the viral transcription. Potential and safe drugs are to be identified to treat SARS CoV2. The present study illustrated the binding capability of the lopinavir on the catalytic binding pocket. Research teams around the world performing their better way to find out the drug and vaccine for COVID 19. It takes more time to prove the potential of new drug which have to come across many trails before recommendation. Alternatively the use of already approved drugs for other viruses may be used as a repurposed drug to find out optimized solution for the present calamities.

\section{Funding Information:}

Authors received no specific funding from any external sources.

Acknowledgement: The authors are thankful to Dr.R.Mothi, Assistant Professor, Electronics and Communication Engineering, Mahendra Engineering College for his support during the writing of 
this article.

\section{References}

[1] Chan KS, Lai ST, Chu CM, Tsui E, Tam CY, Wong MM, et al. Treat- ment of severe acute respiratory syndrome with lopinavir/ritonavir: a multicentre retrospective matched cohort study. Hong Kong Med J 2003;9:399-406.

[2] Cheng VC, Tang BS, Wu AK, Chu CM, Yuen KY. Medical treatment of viral pneumonia including SARS in immunocompetent adult. J Infect 2004;49:262-73.

[3] Chu CM, Cheng VC, Hung IF, Wong MM, Chan KH, Chan KS, et al., HKU/UCH SARS Group. Role of lopinavir/ritonavir in the treatment of SARS: initial virological and clinical findings.

Thorax

2004; 59: $252-6$.

[4] Liu X, Zhang B, Jin Z, Yang H, Rao Z. The Crystal Structure of 2019-nCoV Main Protease in Complex with an Inhibitor N3. Available in: https://www.rcsb.org/structure

[5] Macchiagodena, Pagliai,M. and Procacci, P. 2020. Identification of potential binders of the main protease 3CLpro of the COVID - 19 via structure-based ligand design and molecular modeling. Chemical Physics Letters. 750 (2020) 137489.

[6] Md Fulbabu Sk, Rajarshi Roy, Nisha Amarnath Jonniya, Sayan Poddar \& Parimal Kar (2020) Elucidating biophysical basis of binding of inhibitors to SARS-CoV-2 main protease by using molecular dynamics simulations and free energy calculations, Journal of Biomolecular Structure and Dynamics, DOI: $\underline{\text { 10.1080/07391102.2020.1768149 }}$

[7] Mothay, D., Ramesh, K.V. Binding site analysis of potential protease inhibitors of COVID19 using AutoDock. VirusDis. (2020). https://doi.org/10.1007/s13337-020-00585-Z

[8] Nutho et.al., 2020. Why Are Lopinavir and Ritonavir Effective against the Newly Emerged Coronavirus 2019? Atomistic Insights into the Inhibitory Mechanisms.

[9] Shi,J., Sivaraman,J. and Song, J. Mechanism for controlling the dimer-monomers witch and coupling dimerization to catalysis of the severe acute respiratory syndrome coronavirus 3C-like protease, J. Virol. 82 (2008) 4620-4629.

[10] Wu,G.G., Shu-Chun Cheng, Shiang-Chuan Chen, Juo-Yan Li, Yi-Hsuan Fang, Yau-Hung Chenb and Chi-Yuan Chou. Mechanism for controlling the monomer-dimer conversion of SARS coronavirus main protease. Acta Crystallographica Section D Biological Crystallography. D69, 747-755. 


\section{Contact information of the corresponding author}

Dr.M.Mohan

Professor/Department of Science and Humaninties

Mahendra Engineering College (Autonomous)

Mallasamudrum - 637503

Namakkal District, Tamil Nadu

Mobile: 9486069246

Email: mohanrtt@gmail.com, mohanm@mahendra.info 